\title{
Pekiwewin (coming home): advancing good relations with Indigenous people experiencing homelessness
}

\author{
Jesse Thistle MA, Janet Smylie MD MPH
}

Cite as: CMAJ 2020 March 9;192:E257-9. doi: 10.1503/cmaj.200199

See related article at www.cmaj.ca/lookup/doi/10.1503/cmaj.190777

$\mathbf{T}$ o align with domestic ${ }^{1}$ and international law, ${ }^{2}$ ethics guidelines, ${ }^{3}$ and the Calls to Action of the Truth and Reconciliation Commission of Canada, ${ }^{4}$ development of clinical practice guidelines must be led by First Nation, Métis and Inuit Peoples and informed by their diverse and unique worldviews, practices and experiences. To uphold this principle, we have co-led the development of an Indigenous-specific clinical guideline regarding Indigenous homelessness that is distinct from and complementary to Pottie and colleagues' guideline on health care for homeless people published in CMAJ. In this commentary, we present key elements of this Indigenous guideline, including 4 protocols to guide service providers.

The current state of Indigenous homelessness in Canada highlights the critical importance of recognizing and responding to intersectional oppressions, including colonial policies and impacts. Notwithstanding territorial land ties spanning up to 40000 years, ${ }^{6}$ the First Peoples of what is now known as Canada experience a large and disproportionate burden of homelessness compared with those who have "settled" in Canada over the past 4 centuries. Studies indicate that Indigenous people are 8 times more likely to be homeless than non-Indigenous people and represent between $10 \%$ and $80 \%$ of the total homeless population in large urban centres. ${ }^{7,8}$ These numbers almost certainly underrepresent the true magnitude of Indigenous homelessness. ${ }^{7-9}$ The current paucity of specialized Indigenous-led strategies and resources to address Indigenous homelessness, including the absence of Indigenous-specific policy in Canada's National Housing Strategy, is clearly in tension with population-based needs, current domestic ${ }^{1,4}$ and international ${ }^{2}$ policy, and evidence showing that Indigenous leadership and participation is a critical component of successful programming for Indigenous Peoples. ${ }^{7,10}$

Indigenous historian and coauthor Jesse Thistle, author of Definition of Indigenous Homelessness in Canada, ${ }^{11}$ applies an Indigenous lens to homelessness, which he frames as a breakdown of healthy relationships with self, family, community, land, water, place, animals, culture and language resultant from colonial disruptions. This contrasts with standard definitions, which focus on

\section{KEY POINTS}

- In Canada, Indigenous people are 8 times more likely to be homeless than non-Indigenous people and represent $10 \%-80 \%$ of the total homeless population in large urban centres.

- The roots of Indigenous homelessness involve colonial disruptions of relationships with self, family, community, land, water, place, animals, culture and language.

- Responses to Indigenous homelessness need to be led by Indigenous Peoples and grounded in Indigenous worldviews and practices.

- Indigenous protocols regarding relationships provide a strong and practical framework for health and social service providers working with Indigenous people who are experiencing homelessness.

- The life experience of Indigenous people who are or have been homeless is an invaluable gift that can enrich communities and teach providers.

housing precarity or lack of habitation structure. We have built on this framework to develop Indigenous-specific clinical guidelines. Our methods are Indigenous and purposefully different from the Delphi and systematic literature review methods used by Pottie and colleagues, ${ }^{5}$ which draw on non-Indigenous paradigms and are subject to a publication bias in health sciences that marginalizes Indigenous community voices, experiences and perspectives.

In the development of our methods, we faced a familiar dilemma in applied Indigenous health research. Indigenous knowledge systems are diverse and rooted in complex and localized sociocultural-linguistic contexts and ecosystems, so generalizability, despite its high value among non-Indigenous health scientists, needs to be approached with caution. Guided by project Elder and Indigenous community research methodologist Maria Campbell, and with the support of a national advisory committee of Indigenous scholars and people with lived and living experiences of homelessness, we advanced a MétisCree ceremonial research method ${ }^{12}$ that built on natural laws 
and aligned with our own Métis-Cree identities. We refined our geographic focus and concentrated data collection in Saskatoon and Winnipeg, cities that have strong connections to Cree and Métis Peoples. Following a systematic review of the literature on Indigenous homelessness, we interviewed Indigenous people with lived and living experience of homelessness along with doctors and service providers caring for them in Saskatoon and Winnipeg using Indigenous conversational methods. Transcripts were then thematically analyzed using a critical, decolonizing Métis-Cree lens. ${ }^{12}$

To advance knowledge and policy for Indigenous Peoples outside of our own contexts and circles would violate inter-nation protocols. We therefore aimed to model an approach and methods that could be modified by Indigenous communities in other regional territories according to their own distinct worldviews and linked social systems. Although our findings and recommendations are purposefully nongeneralizable, with local adaptation they may be scalable. The strong local rooting of our methods facilitates translation into local policy and practice.

The question remaining was how to translate our layered and complex study findings into easily understood and adaptable recommendations for non-Indigenous health and social service providers. We drew on Indigenous scholarship investigating treaty and pretreaty inter-nation relationships. ${ }^{13}$ Central to Indigenous laws governing relationships is the concept of interrelationality - the notion that all things, animate and inanimate, are connected. ${ }^{11}$ Each Indigenous nation has specific protocols or instructions for behaviour that uphold these laws. Prerequisite to the initiation of interpersonal and inter-nation transactions, such as trading or health service provision, is the need to establish oneself as a good relative, by following protocols. Applying this Indigenous law approach, we grouped our study results into 4 protocols to be followed by health and social service providers working with Indigenous people experiencing homelessness: situating one's self, keeoukaywin (visiting), hospitality, and treat people as you would treat your own relative.

We are currently working with local communities to refine a set of linked recommendations to guide the implementation of these protocols at both individual health care provider and organizational or systems levels. For the purposes of this commentary, we will provide a brief illustration of how they can be applied in day-to-day practice.

The protocol of "situating one's self" may be illustrated by the example of a non-Indigenous doctor, who has spent time educating herself about colonial history and taken evidencebased cultural safety training, introducing herself by self-locating as a guest who works in a host Indigenous territory.

"Visiting" involves ensuring adequate time with each patient so that the provider is not rushed, and ensuring the client's comfort, for example, by offering them water or a cup of tea before getting started. First asking, "What can I do for you today?" and attending to any immediate material, physical or emotional needs (e.g., food, bus fare, foot care, acute physical ailments or acute emotional distress) is important, as is showing kindness and empathy throughout the client's visit. Elder Campbell reminded us that people commonly feel scared, ashamed and vulnerable, and lack confidence when they are homeless. They may be dirty and hungry, in which case a meal, shower and set of clean clothes are essential preconditions for good visiting (Elder Maria Campbell: personal communication, 2020).

"Hospitality" is shown by a facility being Indigenous-specific with features, symbols and artwork of the local territory - and having mostly Indigenous staff, who are welcoming to all. Diversity of Indigenous identities and experiences can be safely shared and respected. Judgment, including "hot-spotting" (an unproven practice in health care in which providers attempt to identify high-cost patients and reduce costs while improving care) or labelling people would be actively discouraged. Food, socks, clothing, laundry and bathing facilities are available on site or readily accessible elsewhere. Ensuring safety, including safe travel, and prescribing shelter would be required parts of every encounter.

To "treat people as you would treat your own relative" is to treat all clients with kindness, respect and dignity, actively and reflectively listening to each client's story with an open mind, heart and spirit, and applying a client-directed, strength-based approach. Providers recognize and respond to the importance of nurturing relationality with self, family of origin or choice, land and web of all things, and reflect often on what might need to change at a systems level to better support clients. Elder Campbell shared that treating everything in creation as a relative is the essence of the Métis-Cree kinship, or wahkotowin, and that kindness, respect and dignity are the prime guiding principles (personal communication, 2020).

During one of our project ceremonies, Elder Campbell shared a story about how we have always had people who left our communities to travel. When they returned home, the community was enriched by the new knowledge, experiences and skills that they had acquired while away. It is time for Indigenous people experiencing homelessness to be welcomed home and recognized as the knowledge carriers they are. Their life experience is an invaluable gift that can enrich lives and physicians' toolkits and be applied to helping and healing in community. A long time ago, following a talking circle, Elder Campbell's own teacher asked her why she had not spoken up in the circle. She told him she was too ashamed and that she did not think that she had anything to contribute - that he was the one who held knowledge. He responded that he was an old man and that he could not help the people who she could help because he did not have that lived or living experience (personal communication, 2020). People experiencing homelessness, too, are uniquely situated to help themselves and enrich their health care delivery.

The considerable work of pekiwewin, or coming home, needs to be led by Indigenous Peoples but will be successful only if non-Indigenous service providers, decision-makers and organizations are willing to engage on their own journeys of change.

\section{References}

1. Constitution Act, Section 35; Part II Rights of the Aboriginal Peoples of Canada; 1982.

2. United Nations declaration on the rights of Indigenous Peoples. New York: UN General Assembly; 2007. 
3. Canadian Institutes of Health Research, Natural Sciences and Engineering Research Council of Canada, and Social Sciences and Humanities Research Council. Research involving the First Nations, Inuit, and Métis Peoples of Canada. In: Tri-Council policy statement: ethical conduct for research involving humans; 2018. Available: www.pre.ethics.gc.ca/eng/documents/tcps2 -2018-en-interactive-final.pdf (accessed 2020 Feb. 5).

4. Honouring the truth, reconciling for the future: summary of the final report of the Truth and Reconciliation Commission of Canada. Winnipeg: The Truth and Reconciliation Commission of Canada; 2015.

5. Pottie K, Kendall CE, Aubry T, et al. Clinical guideline for homeless and vulnerably housed people, and people with lived homelessness experience. CMAJ 2020;192:E240-54.

6. Morlan RE. Old Crow Basin. In: The Canadian Encyclopedia. Toronto: Historica Canada; 2012 [last edited 2015 Mar. 4]. Available: www.thecanadianencyclopedia .ca/en/article/old-crow-basin (accessed 2020 Feb. 13).

7. Belanger Y, Awosoga O, Weasel Head G. Homelessness, urban Aboriginal people, and the need for a national enumeration. Aborig Policy Stud 2013;2:4-33.

8. Toronto street needs assessment 2018: results report. Toronto: City of Toronto; 2018. Available: www.toronto.ca/wp-content/uploads/2018/11/99be-2018 -SNA-Results-Report.pdf (accessed 2020 Feb. 5).

9. First Nations, Métis, and Inuit Urban and Rural Homelessness policy statement. Peterborough (ON): Ontario Aboriginal Housing Services; 2016. Available: www.ontarioaboriginalhousing.ca/wp-content/uploads/2016/08/OAHS-FNMI -Homelessness-Policy-Statement-Final.pdf (accessed 2020 Feb 5)

10. Smylie J, Kirst M, McShane K, et al. Understanding the role of Indigenous community participation in Indigenous prenatal and infant-toddler health promotion programs in Canada: a realist review. Soc Sci Med 2016;150:128-43.

11. Thistle J. Definition of Indigenous homelessness in Canada. Toronto: Canadian Observatory on Homelessness Press; 2017.

12. Thistle J, Laliberte N, Weissman E, et al. Pekiwewin (coming home): clinical guidelines for health and social service providers working with Indigenous Peo- ple experiencing homelessness, executive summary. Toronto: Well Living House; 2020. Available: www.welllivinghouse.com/what-we-do/projects/pekiwewin -coming-home-clinical-guidelines-for-health-and-social-service-providers-working -with-indigenous-people-experiencing-homelessness/?preview=true (material accessed 2020 Feb. 5).

13. Koleszar-Green R. What is a guest? What is a settler? Cult Pedagog Inq 2019;10: 166-77.

Competing interests: Jesse Thistle received a modest stipend from the Inner City Health Associates research grant for the Pekiwewin project, which was held at the Well Living House research unit, St. Michael's Hospital, Unity Health Toronto. This stipend supported his work on the Pekiwewin clinical guideline. He also received some funds from the Pierre Elliott Trudeau Foundation after the project was completed. No other competing interests were declared.

This article was solicited and has not been peer reviewed.

Affiliations: Department of Equity Studies (Thistle), York University; Dalla Lana School of Public Health (Smylie), University of Toronto; Well Living House, Centre for Urban Health Solutions, and Department of Family and Community Medicine (Smylie), St. Michael's Hospital; Unity Health Toronto (Smylie), Toronto, Ont.

Contributors: Jesse Thistle contributed key concepts and provided formative input on all drafts. Janet Smylie led the first draft of the manuscript and integrated feedback to produce the final manuscript. Both authors gave final approval of the version to be published and agreed to be accountable for all aspects of the work.

Correspondence to: Janet Smylie, janet.smylie@utoronto.ca 